\title{
RANCANG BANGUN APLIKASI SIMPAN PINJAM KOPERASI KARYAWAN PADA PT. AMAS SAMUDRA JAYA
}

\author{
Refy Rizky Januari ${ }^{1}$, Naely Farkhatin ${ }^{2}$ \\ ${ }^{1,2}$ Teknik Informatika, Fakultas Teknik dan Ilmu Komputer, Universitas Indraprasta PGRI Jakarta \\ Jalan Raya Tengah No 80, Kelurahan Gedong, Pasar Rebo, Jakarta Timur \\ 1refyrizkijanuari@gmail.com, ${ }^{2}$ naely_farkhatin@yahoo.com
}

\begin{abstract}
ABSTRAK
Permasalahan yang terdapat pada PT. Amas Samudra Jaya yaitu proses administrasi simpan pinjam koperasi karyawan PT. Amas Samudra Jaya masih menggunakan sistem manual dimana pencatatan dan laporan masih dilakukan dengan pencatatan ke dalam buku dan sulitnya cara mengetahui anggota yang memiliki simpan/ pinjam karena masih menggunakan pembukuan secara manual sehingga sulit untuk mengetahui anggota yang masih menyimpan atau pun meminjam. Tujuan merancang suatu aplikasi simpan pinjam koperasi karyawan ini dengan tujuan untuk memudahkan admin dalam memproses pengolahan data yang ada saat ini. Perangkat aplikasi yang telah dibuat dengan bahasa pemrograman Java NetBeans 8.0.2 dan penyimpanan data pada database MySQL dapat memberikan kelancaran dalam proses menginput dan penyimpanan data-data serta laporan-laporan yang diberikan kepada pimpinan perusahaan. Dengan menggunakan metode pengembangan sistem yaitu Waterfall dalam penelitian ini adalah dengan tahapan-tahapan seperti rekayasa sistem, analisis, desain, coding, testing, dan maintenance. Hasil dari penelitian ini menciptakan suatu sistem yang dibangun berdasarkan pertimbangan kebutuhan yang ada di koperasi dirancang agar mempermudah pekerjaan staff admin. Jadi, jika sewaktu-waktu ada perubahan data admin sudah mengerti dan paham dengan rancangan sistem tersebut.
\end{abstract}

Kata Kunci: Aplikasi, Koperasi, Simpan Pinjam, Karyawan

\begin{abstract}
The problems that exist in PT. Amas Samudra Jaya is the administrative process of saving and loan cooperative employees of PT. Amas Samudra Jaya still uses a manual system where recording and reports are still done by recording into a book and it is difficult to find out which members have savings/loans because they still use manual bookkeeping so it is difficult to find out which members are still saving or borrowing. The purpose of designing an employee cooperative savings and loan application is to make it easier for admins to process the current data processing. Application tools that have been created using the Java NetBeans 8.0.2 programming language and data storage in the MySQL database can provide smooth processing of input and storage of data and reports provided to company leaders. By using the system development method, namely Waterfall, in this research, the stages are systems engineering, analysis, design, coding, testing, and maintenance. The results of this study create a system that is built based on consideration of the needs that exist in the cooperative designed to facilitate the work of the admin staff. So, if at any time there is a change in data, the admin already understands and understands the design of the system.
\end{abstract}

Key Word: Application, Cooperative, Saving and Loan, Employee

\section{PENDAHULUAN}

Perkembangan zaman semakin modern, canggih dan serba cepat yang membuat aktifitas diseluruh bidang atau sektor kehidupan akan semakin maju. Teknologi dikembangkan untuk membantu manusia mempermudah semua aktifitasnya, diantaranya yang paling banyak dilakukan manusia adalah penyimpanan data (Puspitasari, 2016). Penyimpanan data diperlukan di berbagai tempat, seperti rumah sakit, instansi, bahkan di rumah kita. Penyimpanan data di kantor harus tersusun rapi untuk memudahkan pencarian. Data yang masih tersimpan manual seperti dalam tumpukan kertas yang begitu banyak kadang-kadang sulit untuk ditemukan. Maka dari itu, sudah banyak kantor yang sudah mengguankan computer sebagai media penyimpanan data. Selain tidak memakan banyak tempat, waktu yang dibutuhkan untuk mencari data pun relative singkat (Nurhayati, Josi, \& Hutagalung, 2018).

Sekarang ini banyak program-program yang dibuat untuk mempermudah kita menyimpan 
dan mencari data yang kita butuhkan (Astuti \& Devitra, 2017). Kita tidak lagi dipusingkan dengan tumpukan kertas, banyaknya arsip yang menumpuk terlebih ketika kita akan melakukan proses pengolahan data yang banyak memakan tempat dan membutuhkan waktu yang cukup lama untuk mencarinya. Komputerisasi adalah pemanfaatan komputer secara benar dan semaksimal mungkin, bukan hanya sekedar pengganti mesin ketik. Hal ini harus ditunjang oleh hardware (perangkat keras), software (perangkat lunak) dan brainware (operator/pemakai). Untuk masa sekarang ini ketiga faktor tersebut saling berkaitan dan harus terpenuhi semua agar komputer dapat menjalankan tugas dan fungsinya secara optimal (Sujono, Mayasari, \& Koloniawan, 2019).

Koperasi Simpan Pinjam Karyawan PT. Amas Samudra Jaya adalah tempat penelitian penulis, dalam penelitian ini dapat disimpulkan dan dijelaskan pengolahan database, yaitu program aplikasi koperasi dimana transaksi yang dilakukan pada koperasi tersebut, masih menggunakan sistem manual, dikarenakan belum adanya aplikasi yang mendukung (Widiati, 2017). Diantaranya bagaimana cara penyimpanan data simpan pinjam baik menabung maupun mengambil pada simpanan pokok dan simpanan wajib, dari hasil pengolahan jual beli serta simpanan lainnya. Dalam penelitian kali ini, koperasi tersebut yang berada di bawah naungan Yayasan Amas Samudra Jaya merupakan koperasi yang bergerak di bidang simpan pinjam dan setiap karyawan beserta jajaran staf lainnya akan menjadi pegawai koperasi yang merupakan anggota koperasi (Wati \& Siahaan, 2017).

Dengan permasalahan tersebut, perlu ada nya suatu sistem yang terkomputerisasi dalam penyelesaiannya. Sistem adalah sekelompok unsur yang erat hubungannya satu dengan yang lain, yang berfungsi bersama-sama untuk mencapai tujuan (Sutabri, 2012). Sistem merupakan suatu kumpulan dari komponen-komponen yang membentuk satu kesatuan (Tyoso, 2016). Pembangunan sistem adalah sekumpulan aktivitas yang menggambarkan secara rinci bagaimana sistem akan berjalan. Hal itu bertujuan untuk menghasilkan produk perangkat lunak yang sesuai dengan kebutuhan user (Satzinger, J. W., Jackson, R. B., Burd, n.d.).

Diharapkan dengan adanya suatu sistem informasi dapat menangani permasalahan yang ada di perusahaan tersebut. Sistem adalah setiap sesuatu terdiri dari obyek-obyek, atau unsur-unsur, atau komponen-komponen yang bertata kaitan dan bertata hubungan satu sama lain, sedemikian rupa sehingga unsurunsur tersebut merupakan satu kesatuan pemrosesan atau pengolahan yang tertentu. (Prasojo, 2011)

Aplikasi ini dapat memudahkan pekerjaan petugas koperasi perusahaan dalam melaksanakan pembuatan laporan dan mempercepat dalam proses data pencarian data anggota koperasi, data simpanan, data pencairan, data pembayaran serta data pinjaman pada koperasi karyawan PT. Amas Samudra Jaya.

\section{METODE PENELITIAN}

Peneliti menggunakan metode Research and Development daam penyelesaian penelitian ini. (Sugiyono, 2016). Dalam pelaksanaan $\mathrm{R} \& \mathrm{D}$, ada beberapa metode yang digunakan yaitu metode deskriptif, evaluatif dan eksperimental. Metode penelitian deskriptif digunakan dalam penelitian awal untuk menghimpun data tentang kondisi yang ada yaitu penulis membutuhkan data-data yang dapat menunjang tercipta nya suatu sistem informasi usaha simpan pinjam koperasi seperti data anggota, data simpanan, data pinjaman dan data pembayaran angsuran terdahulu yang masih tersimpan secara manual didalam buku besar. Metode evaluatif digunakan untuk mengevaluasi proses ujicoba pengembangan suatu produk, dalam proses ini penulis melakukan ujicoba terhadap suatu sistem yang telah dirancang agar tidak ada terjadi kesalahan dalam proses penginputan data serta pelaporan bulanan kepada kepala koperasi. Dan metode eksperimen digunakan untuk menguji keampuhan dari produk yang dihasilkan, dalam proses yang terakhir ini perlu dilakukan pengujian akhir yang diharapkan bahwa sistem yang dirancang oleh penulis dapat berjalan dengan baik dan sesuai dengan kebutuhan dan terfokus pada proses simpan pinjam koperasi karyawan PT. Amas Samudra Jaya (Putra, 2011). 
HASIL DAN PEMBAHASAN

\section{Alternatif Penyelesaian Masalah}

Berdasarkan masalah-masalah yang telah dianalisa pada Koperasi Karyawan PT. Amas Samudra Jaya, maka penulis memberikan alternatif penyelesaian masalah, yaitu:

1. Perancangan sistem informasi simpan pinjam yang terkomputerisasi harus segera dilaksanakan sehingga dapat menghasilkan informasi yang cepat, tepat dan akurat.

2. Perancangan database secara komputerisasi untuk sistem informasi simpan pinjam sehingga mempermudah penyimpanan data tidak menggunakan media kertas lagi melainkan berupa hard disk atau media penyimpanan elektronik lainnya.

3. Perlunya sumber daya manusia yang terampil agar mampu membuat dan menjalankan sistem informasi simpan pinjam dengan baik dan rapih.

4. Membuat sistem informasi simpan pinjam yang mudah dipahami oleh setiap user agar kinerjanya lebih cepat dalam menghasilkan laporan.

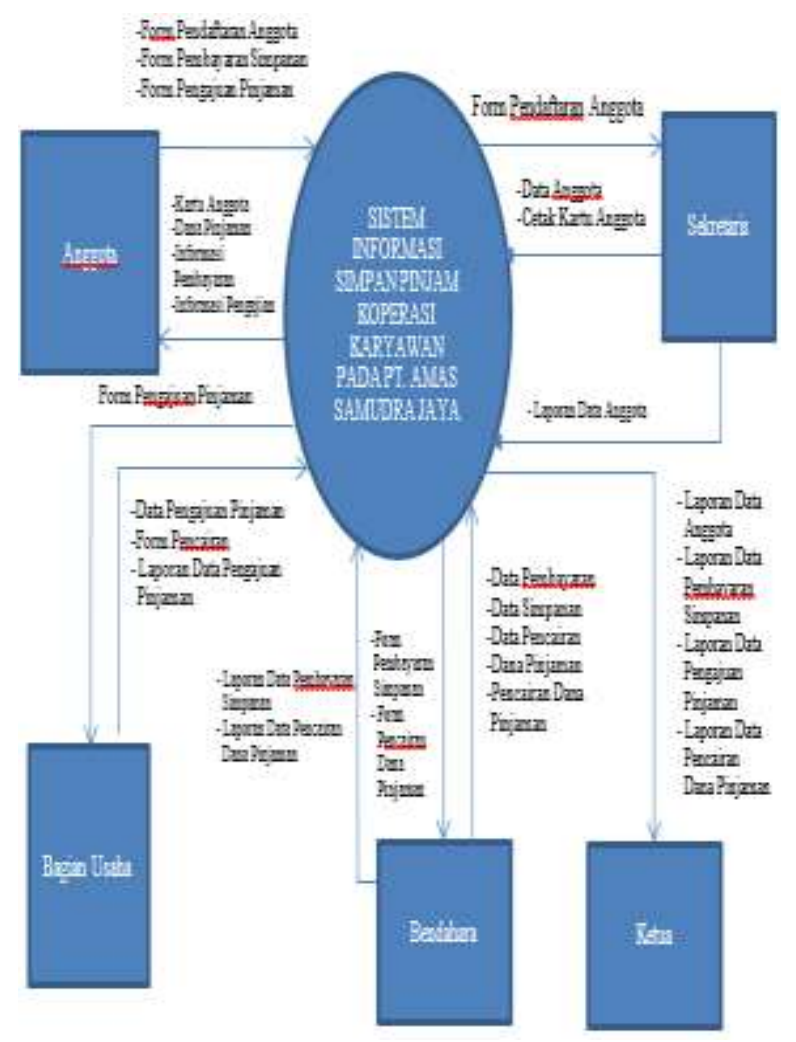

Gambar 1. Diagram Konteks

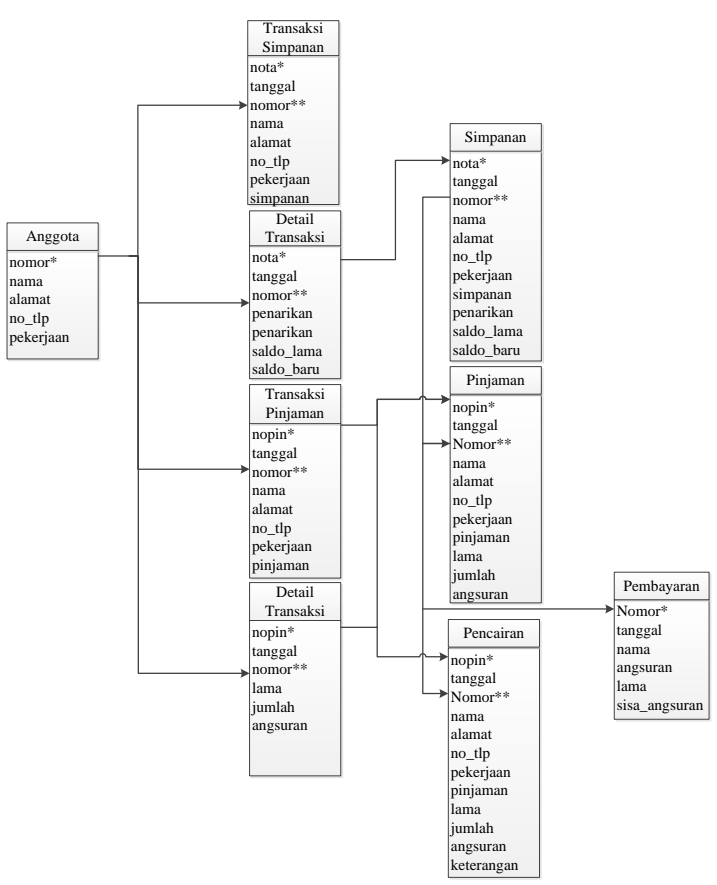

Gambar 2. Normalisasi

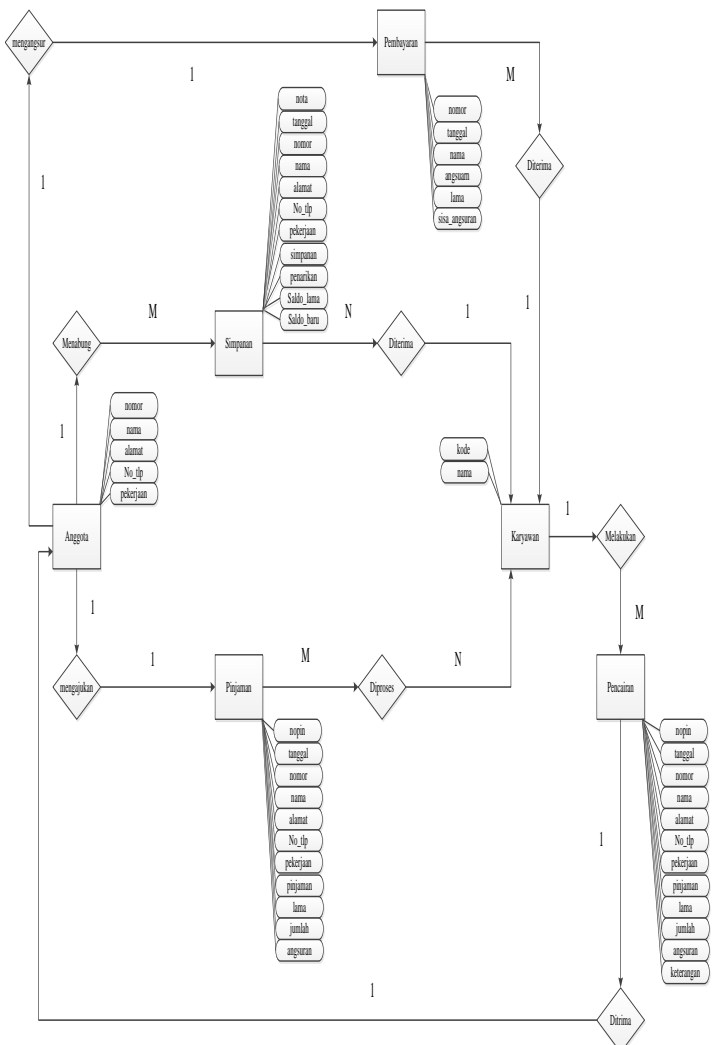

Gambar 3. ERD (Entity Relationship Diagram)

Berikut adalah tampilan layar dan hasil pengujian pada software program yang telah di buat dengan bahasa pemrograman Java. 


\section{AMAS}

SISTEMINFORMASI KOPERASI SIMPAN PINJAM

KOPERISI KARYAWANPT. AMAS SAMUDRALAYA

\section{Gambar 4. Form Menu Utama}

Layar di atas menampilkan tampilan Menu Utama pada Sistem Informasi Koperasi Simpan Pinjam Karyawan PT. Amas Samudra Jaya. Pada layar utama tersedia menu bar yang terdiri dari master data yang digunakan untuk memasukkan data yang berkaitan dengan data anggota, data simpanan, data pinjaman, data pembayaran dan laporanlaporan.

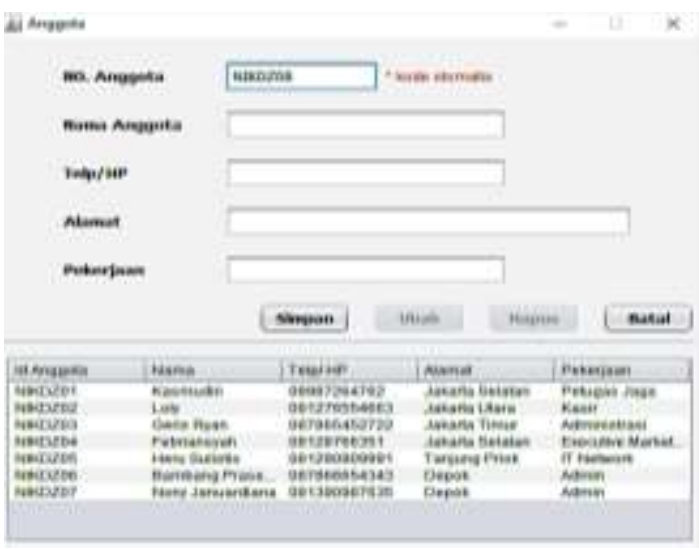

Gambar 5. Form Data Anggota

Layar di atas menampilkan tampilan form data anggota. Pada layar form data anggota untuk meng-input data barang yang terdiri dari ID Anggota, Nama Anggota, Telp, Alamat dan Pekerjaan.

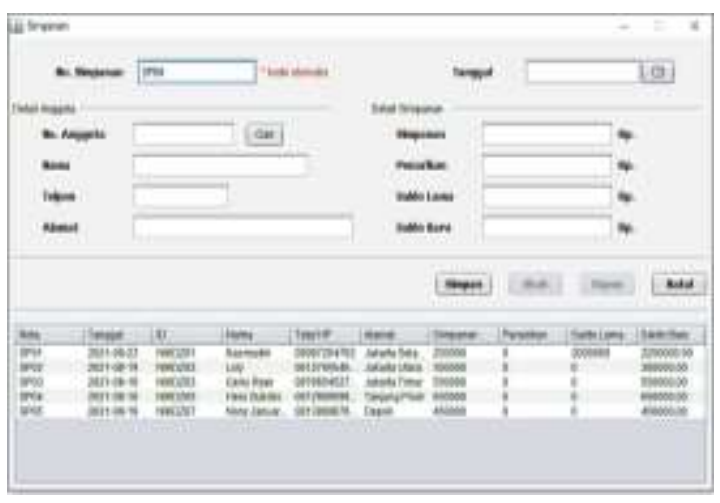

Gambar 6. Form Data Simpanan
Layar di atas menampilkan tampilan form data simpanan. Pada layar form data simpanan untuk meng-input data gudang yang terdiri dari No Simpanan, Tgl Simpanan, No Anggota, Nama Anggota, No Telp, Alamat, Simpanan, Penarikan, Saldo Lama dan Saldo Baru.

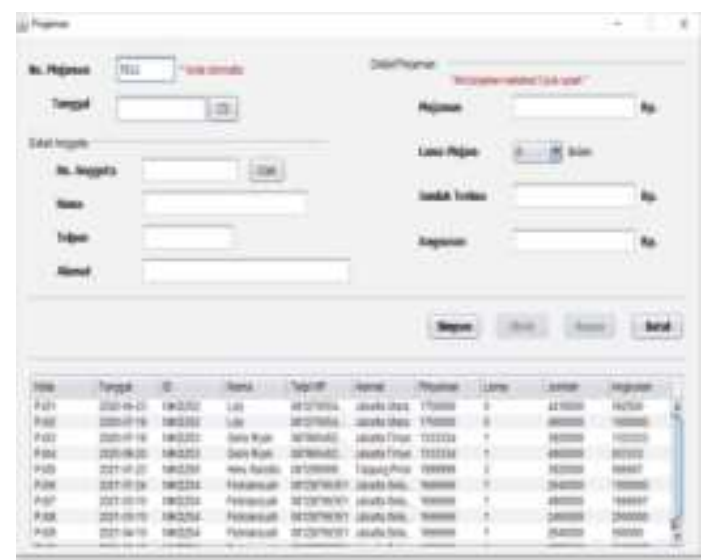

Gambar 7. Data Form Data Pinjaman

Layar di atas menampilkan tampilan form data pinjaman. Pada layar form data pinjaman untuk meng-input data pinjaman yang terdiri dari No Pinjaman, Tgl Pinjaman, No Anggota, Nama Anggota, No Telp, Alamat, Pinjaman, Lama Pinjaman, Jumlah Terima dan Angsuran.

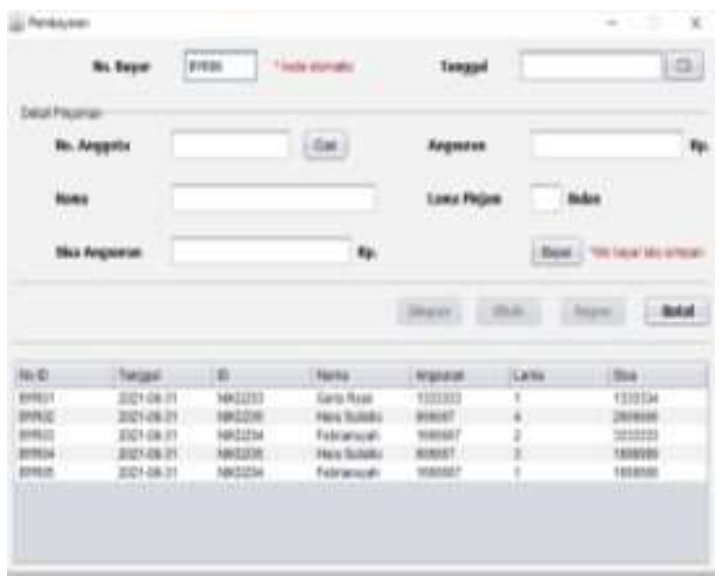

Gambar 8. Form Data Pembayaran

Layar di atas menampilkan tampilan form data pembayaran. Pada layar form data pembayaran untuk meng-input data pembayaran yang terdiri dari No Bayar, Tgl Bayar, No Anggota, Nama Anggota, Sisa Angsuran, Angsuran dan Lama Pinjam. 


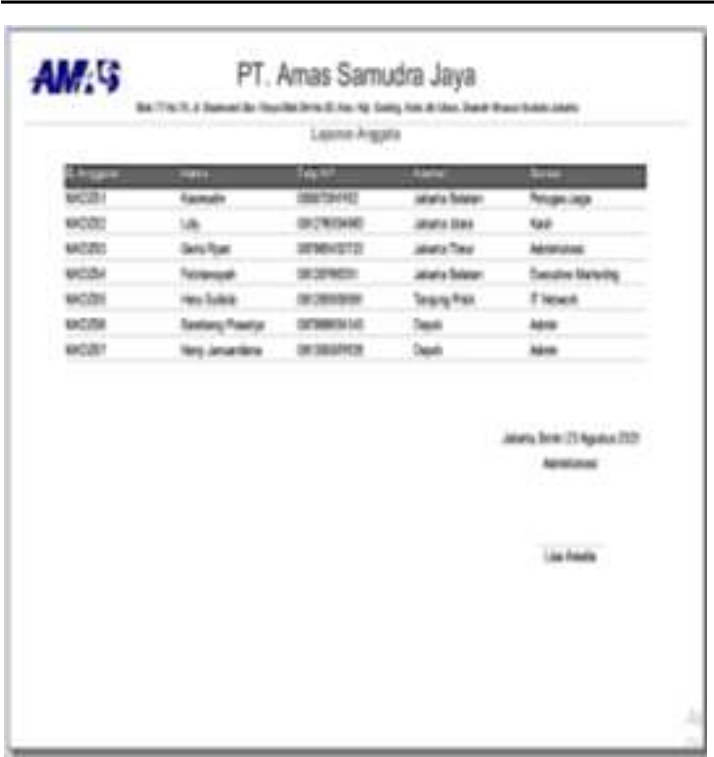

Gambar 10. Laporan Data Anggota

Layar di atas menampilkan tampilan form laporan data anggota. Pada layar form data anggota masuk digunakan untuk mengecek laporan data anggota masuk terdiri ID Anggota, Nama Anggota, No Telp, Alamat, dan Pekerjaan.

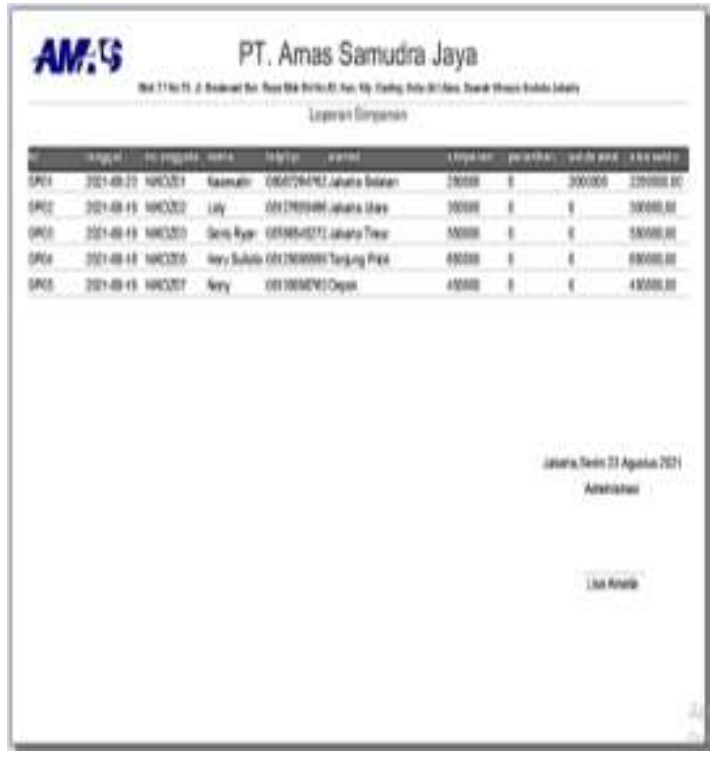

Gambar 11. Laporan Data Simpanan

Layar di atas menampilkan tampilan form laporan data simpanan. Pada layar form data simpanan digunakan untuk mengecek laporan data simpanan terdiri No Simpanan, Tgl Simpanan, No Anggota, Nama Anggota, No Telp, Alamat, Simpanan, Penarikan, Saldo Awal dan Sisa Saldo.

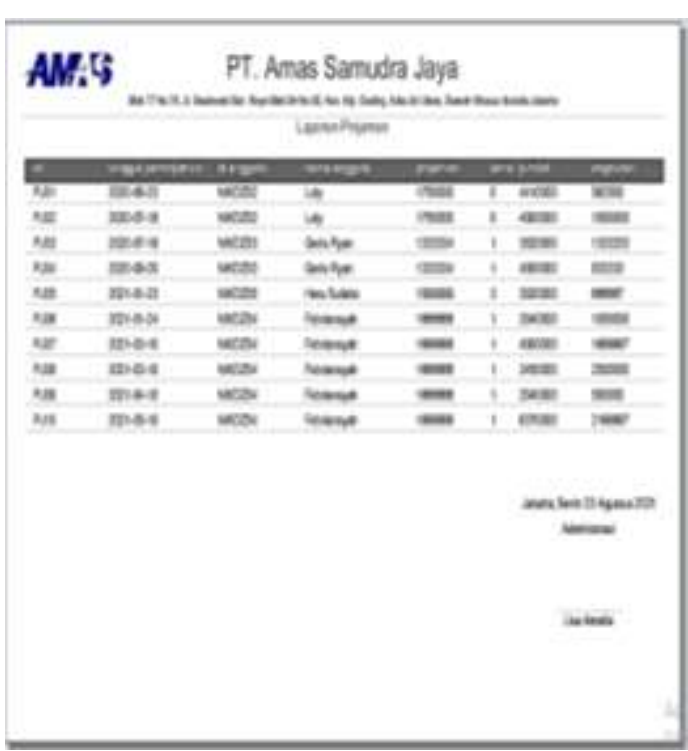

Gambar 12. Laporan Data Pinjaman

Layar di atas menampilkan tampilan form laporan data pinjaman. Pada layar form data pinjaman digunakan untuk mengecek laporan data pinjaman terdiri No Pinjaman, Tgl Pinjaman, No Anggota, Nama Anggota, No Telp, Alamat, Pinjaman, Lama Pinjaman, Jumlah Terima dan Angsuran.

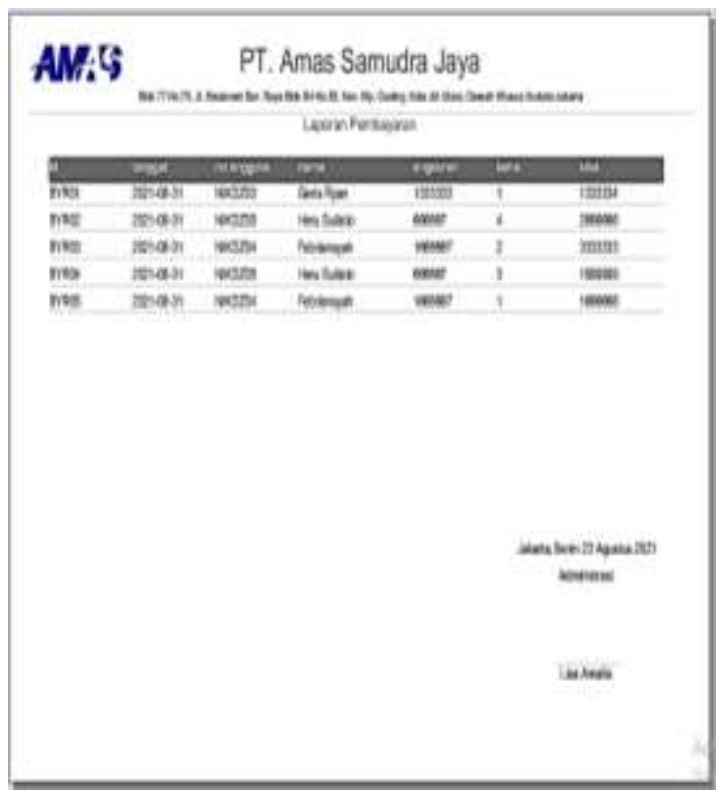

Gambar 13. Laporan Data Pembayaran

Layar di atas menampilkan tampilan form laporan data pembayaran. Pada layar form data pembayaran digunakan untuk mengecek laporan data pembayaran terdiri No Bayar, Tgl Bayar, No Anggota, Nama Anggota, Sisa Angsuran, Angsuran dan Lama Pinjam. 


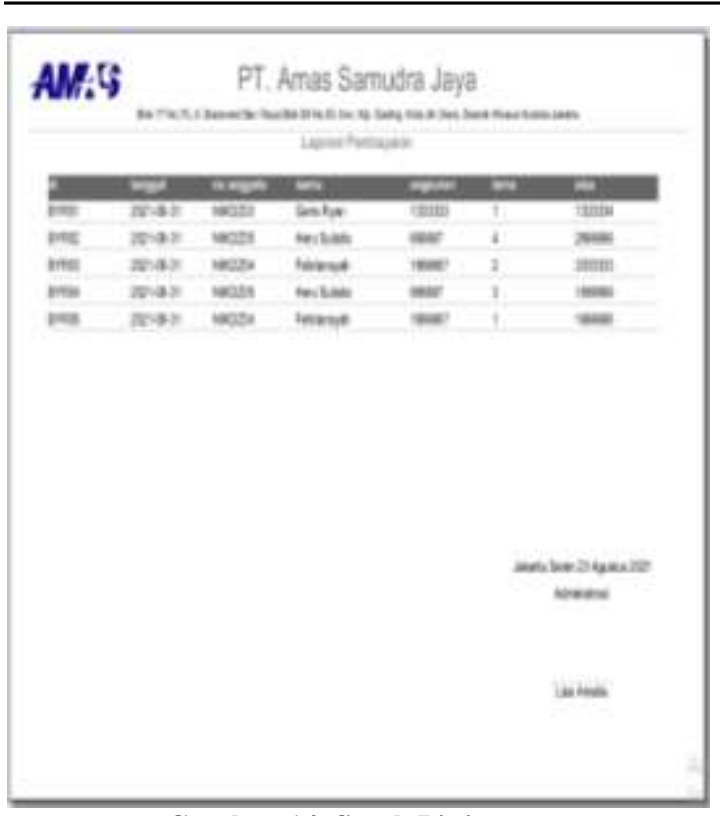

Gambar 14. Struk Pinjaman

Layar di atas menampilkan tampilan form struk pinjamaan. Pada layar form struk pinjaman digunakan untuk mengecek struk pinjaman terdiri Tanggal Pinjaman, Id Anggota, Nama Anggota, Sisa Pinjaman, Lama Pinjaman, Jumlah Pinjaman dan Angsuran.

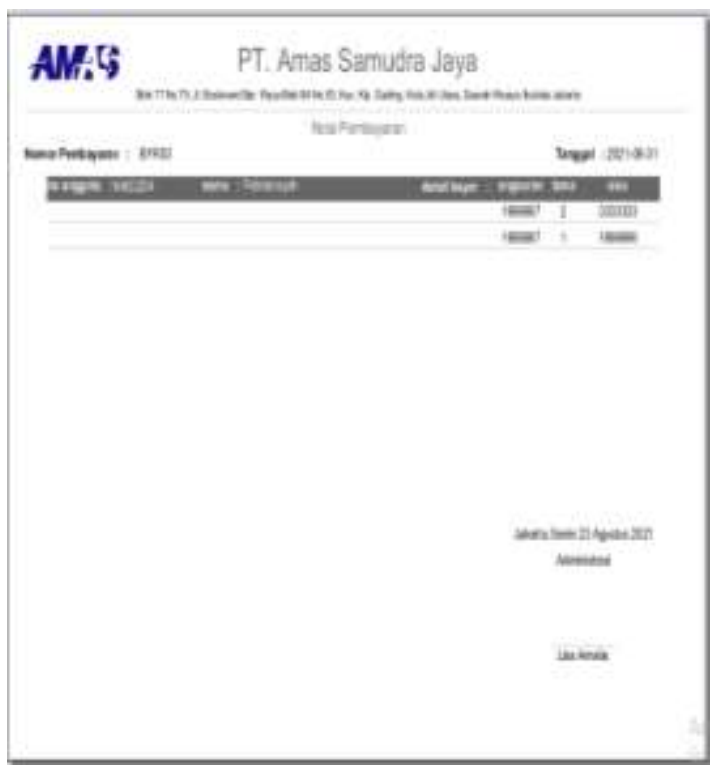

Gambar 15. Nota Pembayaran

Layar di atas menampilkan tampilan form nota pembayaran. Pada layar nota pembayaran digunakan untuk mengecek nota pembayaran terdiri Nomor Pembayaran, Tanggal, No Anggota, Nama Anggota, Angsuran, Lama Pinjaman dan Sisa Pinjaman.

\section{SIMPULAN DAN SARAN}

Sistem Informasi Simpan Pinjam Pada Koperasi PT. Amas Samudra Jaya berbasis desktop dengan menggunakan bahasa pemrograman Java dan MySQL sebagai databasenya. Aplikasi ini dapat membantu bagian admin dalam memudahkan proses pencarian data kinerja jauh lebih baik. Pelaporan data anggota, data simpanan, data pinjaman serta data pembayaran menjadi lebih efektif dan efisien.

Sarannya adalah meskipun telah menggunakan sistem yang terkomputerisasi, ketelitian dalam menginput data perlu diperhatikan agar data yang sudah direkam (store) benar-benar merupakan salinan dari data sumber.

\section{DAFTAR PUSTAKA}

Astuti, D., \& Devitra, J. (2017). Analisis Dan Perancangan Sistem Informasi Simpan Pinjam Pada Koperasi Pegawai Negeri Iain Sultan Thaha Saifuddin Jambi. Manajemen Sistem Informasi.

Nurhayati, A. N., Josi, A., \& Hutagalung, N. A. (2018). Rancang Bangun Aplikasi Penjualan Dan Pembelian Barang Pada Koperasi Kartika Samara Grawira Prabumulih. Jurnal Teknologi Dan Informasi. https://doi.org/10.34010/jati.v7i2.490

Prasojo, M. (2011). Pengantar Sistem Informasi Manajemen. bandung: CV. Remadja Karya.

Puspitasari, D. (2016). Rancang Bangun Sistem Informasi Koperasi Simpan Pinjam Karyawan Berbasis Web. Jurnal Pilar Nusa Mandiri.

Putra, N. (2011). Research and Development, Penelitian dan Pengembangan: Suatu Pengantar. Jakarta: PT Raja Grafindo Persada.

Satzinger, J. W., Jackson, R. B., Burd, S. D. (n.d.). System Analysis and Design in A Changing World. USA: Cengage Learning.

Sugiyono. (2016). Metode Penelitian Kuantitatif, Kualitatif dan $R \& D$. Bandung: PT Alfabet.

Sujono, S., Mayasari, M. S., \& Koloniawan, K. (2019). Prototipe Aplikasi Simpan Pinjam Pada Koperasi Darma Karya Pangkalpinang Babel. Jurnal Sisfokom (Sistem Informasi Dan Komputer). 
https://doi.org/10.32736/sisfokom.v8i1. 609

Sutabri, T. (2012). Analisis Sistem Informasi. Yogyakarta: Andi.

Tyoso, J. S. P. (2016). Sistem Informasi Manajemen. Yogyakarta: DeePublish.

Wati, H. K., \& Siahaan, K. (2017). Analisis Dan Perancangan Sistem Informasi Koperasi Simpan Pinjam Berbasis Web Pada Mts Negeri Talang Bakung Kota Jambi. Jurnal Manajemen Sistem Informasi.

Widiati, W. (2017). Aplikasi Pengolahan Data Koperasi Simpan Pinjam Untuk Meningkatkan Pelayanan Koperasi. IJSE - Indonesian Journal on Software Engineering. 